
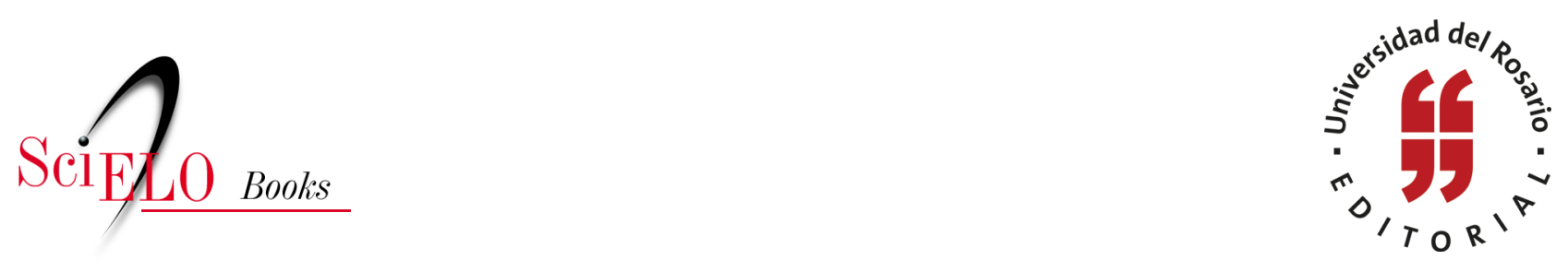

\title{
13. Mi hermanito o la danza ebria
}

\author{
César Augusto Tapias Hernández
}

TAPIAS HERNÁNDEZ, C.A. Mi hermanito o la danza ebria. In: Historias de familia: Etnografía delirante sobre el amor, la violencia y las drogas [online]. Bogotá: Editorial Universidad del Rosario, 2014, pp. 55-56. Textos de ciencias humanas collection. ISBN: 978-958-738-543-4. https://doi.org/10.7476/9789587385434.0014.

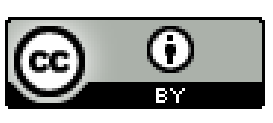

All the contents of this work, except where otherwise noted, is licensed under a Creative Commons Attribution 4.0 International license.

Todo o conteúdo deste trabalho, exceto quando houver ressalva, é publicado sob a licença Creative Commons Atribição $\underline{4.0}$.

Todo el contenido de esta obra, excepto donde se indique lo contrario, está bajo licencia de la licencia $\underline{\text { Creative }}$ Commons Reconocimento 4.0. 


\title{
13. Mi hermanito o la danza ebria
}

\author{
Toda la noche nos la pasamos llorando y bebiendo, y pude \\ decirte borracho las cosas que me bullian del corazón... \\ John Fante, Pregúntale alpolvo
}

Me contaba un profesor de antropología que en India danzar es diferente a bailar. Para lo primero, el cuerpo era nada sin el alma, que agitada debía verse en la danza, de tal forma que no es lo mismo ver la música poseyendo almas, a ver cuerpos sudando en medio de la pista... El alma de mi hermanito se agita, encantadora y sonriente, adornada por dos huequitos que le deja la sonrisa en cada mejilla. Sonriente, mi hermanito se esparce en una noche de farra, aguantando todo el guaro que la noche le brinde, siendo a la vez la danza ebria, danza seductora, armada de una sonrisa, la sonrisa, los huequitos... Pienso en Baco, dios del vino y de la fiesta que en tiempos modernos puede ser cualquiera que se deje llevar por la propia fiesta sin importar dónde termine.

Caliche ha heredado muchos conocimientos de papá, sobre todo la artesanía de soldar, y el arte de la cerrajería, las lucecitas brillantes que despide el hierro cuando se funde de calor... igual que el cucho fue al Sena, una institución pública, donde perfeccionó lo aprendido en el taller de mi padre, junto a él y los ayudantes que tuvo papá: Ernesto, Garbanzo, Jaimito... y en el INEM, de donde salió graduado en la especialidad de metalistería... Soldar y farrear sin muchos problemas, eso hace mi hermano... (eso hace mi cucho...), flotando por la casa callado muchas veces... haciendo ruido muchas otras, siendo silencio y escándalo los fines de semana, entrando a casa ya casi el principio de la otra semana. Y nuestra madre, cada vez, prometiéndose no decirle nada más que suene a cantaleta; pero por quererlo tanto a veces no duerme preocupada pensando en la calentura del barrio y mi hermano farreando. 
Bullicio, farra, “y Carlos no ha entrado”.

Tastaseos, bombardeos, balas entre los combos del barrio, "y Carlos no ha entrado".

Ya quisiera mamá que fueran ovejitas los tastaseos para contarlos buscando el sueño, “y Carlos no ha entrado".

La esperanza es que mi hermano se consiga una mujer que no farree como él.

$\infty \infty \infty$

Para abordar a mi familia como un problema sociológico es necesario hacer precisiones y diferenciar asuntos. Por ejemplo, el objeto de los estudios sociales sobre la familia. ¿Cuál es la tipología de familia analizada? En primer lugar, encontramos estudios sobre la familia consanguínea, un conjunto de miembros unidos por vínculos de parentesco, que comparten un tronco, un apellido; en segundo lugar, podemos leer estudios sobre la familia de residencia, también denominada hogar.

Esta familia de residencia se refiere específicamente a un grupo de personas que, mediante un vínculo (o ninguno) de parentesco, afinidad o amistad, comparten el espacio y organizan conjuntamente la supervivencia (Rico de Alonso, 1999). Para el caso de esta etnografía sobre mi familia, el camino es la primera opción: por allí veremos la familia como un conjunto de miembros unidos por vínculos de parentesco, sin dejar de lado las relaciones individuales y colectivas que establecen con los espacios que ocupan. Un enfoque sistémico que en palabras de Malagoli-Tegliatti (1983), citado por Cusinato (1994), considera la familia el sistema relacional primario en el proceso de individuación, crecimiento y cambio del individuo. Un crecimiento, considerado en el seno del proceso de individuación, crecimiento y cambio de todo el sistema familiar.

Para comprender las relaciones familiares, sin embargo, no se hace explícito cómo se entiende desde la teoría este concepto. En realidad, es difícil encontrar una definición, diversos autores como Cusinato (1992), Gimeno (1999), Satir (1978), Hernández (1998) y Sarmiento (1994) definen la relación como un proceso de interacción entre los miembros de la familia. Para ver esto principalmente veremos el espacio doméstico sin aislarlo de lo público, o fuera de casa: la violencia de la gran ciudad y los conflictos de todo tipo, políticos, económicos... de fuerza... de poder... se manifiestan en nuestro pequeño universo sociológico que no se inscribe solo en el interior de las casas y la violencia doméstica. 